Stanley Weber MD, James H. Acuff MD, Marloochehr Mazloomdoost MD, Bulent I. Kirimli MD

\title{
Transurethral prosta- tectomy complicated by intraperitoneal extravasation of irrigating fluid
}

A patieut underwent transurethral resection of the prostate (TURP), which was complicated at the outset of the procedure by an inadvertent puncture wound of the dome of the bladder and the peritaneum. Shartly after resection was initiated, the patient developed shoulder pain and a tensely distended abdomen, although at this time the serum sodium concentration remained normal. Over the next several howrs the patient developed significant hyponatremia. The prolonged and gradual time course of this development suggests that fiuid and electrolye shifts occurred via diffusian across the peritoneal membrane. This case illustrates a rare but potentially dangerous complication of TURP that requires recognition prior to intiation of appropriate therapy.

The "TUR syndrome" is a well described complication of transurethral resection of the prostate (TURP) ${ }^{1.2}$ The symptomatology is believed to be due to intravascular absorption of bladder irrigation fluid, which may then result in acute water intoxication. Dilutional hyponatremia and hypoosmolarity are thought to be the underlying mechanisms for the symptom complex which can include agitation, confusion, nausea, vomiting, coma, and possibly death. Absorption can occur not only through open prostatic venous sinuses, but via other routes, such as surgically created defects in the prostatic capsule or perforations

\section{Key words}

SURGERY: transurethral resection of prostate; complicATIONS: bladder perforation; hyponatremia.

From the Department of Anesthesiology, Veterans Administration Medical Center, Pittsburgh, Pennsylvania, and the Department of Anesthesiology and Critical Care Medicine, University of Pittsburgh School of Medicine, Pittsburgh, Pennsylvania

Address correspondence to: Dr. Stanley Weber, Department of Anesthesiology, Presbyterian-University Hospital, DeSoto at O'Hara Streets, Pittsburgh, Pennsylvania 15213 of the bladder. ${ }^{3,4}$ Such occurrences can allow significant volumes of irrigation solution to be sequestered in the perivesical and retroperitoneal spaces. ${ }^{1,5,6}$ We describe a case in which a patient developed the gradual onset of severe hyponatremia over a period of several hours after a TURP complicated by bladder perforation and intraperitoneal extravasation of irrigation fluid. This demonstrates a rare variant of the "TUR syndrome," in which the time course for pathophysiological changes seems to be considerably prolonged. Appropriate diagnosis and intervention by the anaesthetist is important to prevent unnecessary morbidity and mortality in this situation.

\section{Case report}

A 63-year-old $70 \mathrm{~kg}$ man underwent TURP. His history included insulin dependent diabetes mellitus treated with daily split doses of lente insulin. His spot blood glucose values were less than $11.1 \mathrm{mmol} \cdot \mathrm{L}^{-1}$ for several days preoperatively. Other medications included indomethacin and amitriplyline. He received no preoperative intravenous fluid therapy. Other preoperative laboratory values included: sodium $141 \mathrm{mmol} \cdot \mathrm{L}^{-1}$, potassium $3.9 \mathrm{mmol} \cdot \mathrm{L}^{-1}$, blood urca nitrogen $5.6 \mathrm{mmol} \cdot \mathrm{L}^{-1}$, creatinine $239 \mu \mathrm{mol}$. $\mathrm{L}^{-1}$, and haemoglobin $94 \mathrm{~g} \cdot \mathrm{L}^{-1}$. His pre-anaesthetic arterial blood pressure was $130 / 70 \mathrm{mmHg}$, with a pulse rate of 100 beats $/ \mathrm{min}$. Preoperative medications included meperidine $50 \mathrm{mg}$ and promethazine $25 \mathrm{mg} \mathrm{IM}$, and lente insulin 25 units $\mathrm{SC}$ (half of usual morning dose)

Intravenous therapy with five per cent dextrose in lactated Ringer's solution was initiated. Spinal anaesthesia with tetracaine $12 \mathrm{mg}$ in hyperbaric dextrose solution was successfully performed with a $22 \mathrm{~g}$ needle at the $\mathrm{L}_{2}-\mathrm{L}_{3}$ interspace. Anaesthesia up to the $\mathrm{T}_{10}$ dermatome was obtained without significant change in blood pressure or pulse rate. After 15 minutes of resection the patient complained of bilateral shoulder and neck pain. At this time it was noted that the arterial blood pressure had decreased to $90 / 60 \mathrm{mmHg}$, with a pulse rate of 92 . The anaesthetist examined the patient and discovered that he had a tensely distended, non-tender abdomen. No 
change in ventilatory pattern was noted. The surgeon was notified and the operation immediately halted. Four litres of three per cent sorbitol irrigation had been used during the procedure, but only about one and a half lites were recovered. A presumptive diagnosis of bladder and peritoneal perforation was made. Laboratory results at this time showed: sodium $134 \mathrm{mmal} \cdot \mathrm{L}^{-1}$, potassium $3.6 \mathrm{mmol} \cdot \mathrm{L}^{-1}$, and serum glucose $15 \mathrm{mmol} \cdot \mathrm{L}^{-1}$. A Foley catheter was inserted, and the patient was taken to the Recovery Room for further evaluation. He was awake and alert, with continued shoulder pain.

The patient was observed closely for several hours in the Recovery Room while the urology team evaluated his condition. Two and a half hours after the first intraoperative laboratory values, the tests were repeated. At this time sodium was $123 \mathrm{mmol} \cdot \mathrm{L}^{-1}$, glucose $28.3 \mathrm{mmol} \cdot \mathrm{L}^{-1}$, and potassium $3.7 \mathrm{mmol} \cdot \mathrm{L}^{-1}$. Because of the patient's hyperglycaemia, we calculated the value of senum sodium that would maintain the same osmolality with a normal blood sugar (i.e., adding $1.6 \mathrm{mmol} \cdot \mathrm{L}^{-1}$ to the sodium value for each $5.5 \mathrm{mmol} \cdot \mathrm{L}^{-1}$ of glucose above the first $5.5 \mathrm{mmol} \cdot \mathrm{L}^{-1}$ ). The adjusted sodjum value was $129 \mathrm{mmol}$. $L^{-1}$. The patient's urine output after three hours in the Recovery Room totalled $15 \mathrm{ml}$, and furosemide $10 \mathrm{mg}$ was administered intravenously. The systolic arterial blood pressure ranged between 120 and $95 \mathrm{mmHg}$, with pulse rates ranging between 80 to 100 .

Two and a half hours later laboratory tests were again repeated. Sodium was $113 \mathrm{mmol} \cdot \mathrm{L}^{-1}$ (1 $19 \mathrm{mmol} \cdot \mathrm{L}^{-1}$ when adjusted for hyperglycaemia), glucose $29.6 \mathrm{mmol}$. $\mathrm{L}^{-1}$, potassium $4.0 \mathrm{mmol} \cdot \mathrm{L}^{-1}$, and haemoglobin $117 \mathrm{~g}$. $\mathrm{L}^{-1}$. No evidence of haemolysis was found. The patient was awake, but restless and nauseated. His urine output was still minimal despite repeated doses of furosemide. A cystogram showed bladder, peritoneum, and colon perforation. At this time he was returned to the Operating Room for exploratory laparotomy

After arterial and central venous pressure monitoring was established (initial CVP $3 \mathrm{mmHg}$ ), rapid sequence induction was performed without difficulty. The initial intraoperative sodium was $115 \mathrm{mmol} \cdot \mathrm{L}^{-1}\left(121 \mathrm{mmol} \cdot \mathrm{L}^{-1}\right.$ when adjusted for hyperglycaemia). Following incision, nearly three litres of clear fluid were removed. Chemical analysis for electrolyte and glucose concentration was not performed. Inspection of the dome of the bladder showed a small perforation, and it was hypothesized that a catheter guide inserted at the outset of the TURP had perforated the bladder dome and entered the colon. The defect was repaired, a loop colostomy was performed, and a suprapubic cystostomy tube placed. Three per cent saline solution $320 \mathrm{ml}$ was given over the next two hours, as well as furosemide $20 \mathrm{mg}$ IV. Immediately after infu- sion of the three per cent saline solution, the sodium was $117 \mathrm{mmol} \cdot \mathrm{L}^{-1}\left(123 \mathrm{mmol} \cdot \mathrm{L}^{-1}\right.$ when adjusted for hyperglycaemia). Central venous pressure rose to $5 \mathrm{mmHg}$. Intraoperative urine output, after the suprapubic cystostomy tube placement, was $400 \mathrm{ml}$.

Postoperatively, the patient was brought to the Intensive Care Unit. Continued therapy consisted of vigorous hydration with normal saline and Plasmanate, and continuous infusion of regular insulin at 10 units $\cdot \mathrm{hr}^{-1}$ until adequate control of the hyperglycaemia was obtained. Antibiotics were started to prevent peritonitis. One hour after the operation, sodium was $120 \mathrm{mmol} \cdot \mathrm{L}^{-1}$ (126 mmol . $\mathrm{L}^{-1}$ when adjusted for hyperglycaemia), and glucose was still $29.4 \mathrm{mmol} \cdot \mathrm{L}^{-1}$. The patient improved gradually throughout the night, and by the following morning his sodium was $133 \mathrm{mmol} \cdot \mathrm{L}^{-1}$ (135 mmol $\cdot \mathrm{L}^{-1}$ adjusted for hyperglycaemia) and his glucose was $14.3 \mathrm{mmol} \cdot \mathrm{L}^{-1}$. The remainder of the postoperative course was uneventful, with normal values for serum sodium and glucose, and the patient attained full recovery.

\section{Discussion}

Perforation of the dome of the bladder during TURP can be associated with intraperitoneal extravasation of irrigation fluid. We found that this can cause metabolic derangement with a time course significantly different from that usually seen in the TURP water intoxication syndrome.

There are no reports in the literature on the incidence of bladder perforation with intraperitoneal extravasation of fluid, but it has been reported as a rare complication. ${ }^{3}$ A study of 2015 TURP's found 23 cases of extravasation (1.1 per cent), without noting the relative incidence of intraperitoneal versus extraperitoneal extravasation. ${ }^{4}$ In a more recent study of 511 successive TURPs a postoperative cystogram was routinely done. A total of $66 \mathrm{per}-$ forations of the bladder neck were found ( 13 per cent), and of these 45 would have gone undetected except for the cystogram (nine per cent). ${ }^{7}$ No perforations of the bladder dome were found. These studies present no evidence that bladder neck perforation (a more common occurrence) can be associated with the clinical situation described above for bladder dome perforation.

In this case, perforation of the bladder done resulted in the placement of nearly $3 \mathrm{~L}$ of three per cent sorbitol solution into the patient's peritoneal cavity. The clinical presentation included shoulder pain (probably due to diaphragmatic irritation), a moderate decrease in blood pressure, and a tense, distended, non-tender abdomen. Although initial measurement of serum sodium showed a minimal decline (from $14 \mathrm{l}$ to $134 \mathrm{mmol} \cdot \mathrm{L}^{-1}$ ), subsequent measurements showed a continuous graduad decrease over a period of six hours, reaching a minimum value of 
$113 \mathrm{mmol} \cdot \mathrm{L}^{-1}$. Treatment with furosemide resulted in minimal urine output through the Foley catheter, possibly due to unine extravasation from the bladder into the periconeum. The patient suffered from nausea, restlessness, and shoulder pain, but remained haemodynamically stable and dic' not lapse into confusion or coma. His hyperglycaemia was probably stress-related, as he was a brittle, insulin-dependent diabetic. After a six-hour period of evaluation and unsuccessful conservative therapy, the patient's abdomen was surgically explored. Removal of the peritoneal fluid, placement of a suprapubic cystostomy catheter, and hypertonic saline administration led to reversal of the hyponatremia.

This case illustrates several important points about the diagnosis and treatment of this complication of TURP. Some of these points were made hy Desmond ${ }^{8}$ in a review of this topic. Regional anaesthesia facilitates the early detection of mental status change or diaphragmatic irritation. Also, careful measurement should be made of the yolume of irrigation solution entering and exiting the patient's bladder, and the abdomen should be intermittently examined for signs of distention. The operating urologist may note an abnormal irrigating pattern when this situation occurs. Such findings should trigger immediate investigation.

There are differences of opinion concerning the need for, and the timing of, surgical intervention in such cases. Mulkey and Witherington ${ }^{9}$ presented eight cases of vesical rupture that were successfully managed with only an indwelling urethral catheter and antimicrobial therapy. Others ${ }^{2,10,11}$ have presented similar findings. Kenyon ${ }^{2}$ suggests that in the case of extensive perivesical extravasation or intraperitoneal involvement, a urethral catheter should be introduced as soon as the diagnosis is made and the patient should receive supportive treatment for four to six hours. After this time, surgical intervention may be carried out more safely. The urologic surgeons at our institution elected to attempt conservative treatment of the bladder perforation. However, the subsequent discovery of a colon perforation by the cystogram made exploratory laparotomy mandatory.

The finding of a slow and gradual development of hyponatremia was unexpected. Because the pathophysiology leading to such hyponatremia is probably not unique to this case, we now belicve that the diagnosis of bladder perforation with intraperitoneal extravasation of imigation solution calls for therapy including immediate removal of the fluid. Such action will probably prevent the gradual onset of hyponatremia. In contrast, treatment of the developing hyponatremia with furosemide (especially prior to placement of a suprapubic cystostomy catheter) may not be helpful because extravasation of urine into the peritoneum can occur. The net effect on hyponatremia due to vigorous renal sodium and water excretion followed by peritoneal reabsorption of the resulting fluid is unpredictable.

\section{References}

I Aashein $G M$. Hyponatremia during transurethral surgery. Can Anaesth Soc J 1973; 20: 274-80.

2 Marx GF, Orkir $L R$. Complications associated with transurethral surgery. Anesthesiology 1962; 23: 802-13.

3 Kenyon $H R$. Perforations in transurethral operations; technic for immediate diagnosis and management of extravasations. JAMA 1950; 142: 798-803.

4 Holigrewe $H L$, Vak $W L$. Factors influencing the mortality and morbidity of transurethral prostatectomy: a study of 2,015 cases. J UJrol 1962; 87: 450-9.

5 Oester A. Madsen PO. Determination of absorption of irrigating fluid during transurethral resection of the prostate by means of radioisotopes. J Urol 1969; 102: 714-9.

6 Conger $K B$. Karafin $L$. A study of irrigating medium extravasation during transurethral surgery. J Urol 1957; 78 : 633-43.

7 Kolonsy Z, Csapo Z, Bladder neck perforations caused by TURP. J Urol Nephrol 1983; 76: 65-73

8 Desmond $J$. Complications of Iransurethral prostatic surgery. Can Anaesth Soc J 1970; 17: 25-36

9 Mulkey AP, Witheringion $R$. Conservative management of vesical rupture. Urology $1974 ; 4: 426-30$.

10 Mitchell JP. Trauma to the urinary tract. Br Med J 1971; 2: 567 .

I1 Cass AS, Ireland GW. Bladder trauma associated with pelvic fractures and severely injured patients. J Trauma 1973; 13: 205 .

\section{Résumé}

Un patient a subi une résection transuréthrale de sa prostate (TURP) s'étant compliqué par une perforation accidentelle du sommet de la vessie et du péritoine. Peu après le déburt de la résection le patient a développé une douleur à l'épaule ainsi qu'un abdomen tendu. A ce siade le sodium sérique éraif normal. Au cours des heures suivantes le patient a developpé une hyponatrémie significative. Le temps d'installation prolongé et graduel de cétte hyponatrémie suggère que le transfert de liquide et électrolytes est survenu par diffusion d̀ travers le péritoine. Ce cas illustre une complication rare et potentiellement dangereuse de la résection transturéthrale de la prostate et dont la detection doit se faire avant le début du traitemen. adéquas. 